\title{
Managing an Unhappy Patient
}

\author{
Viral Desai ${ }^{1,2,3,4}$ \\ ${ }^{1}$ Cosmetic Plastic Surgery and Laser Super specialities, Mumbai, \\ Maharashtra, India \\ 2 Desai Hospitals Ventures LLP, Mumbai, Maharashtra, India \\ 3 Desai Hospitals Private Limited, Mumbai, Maharashtra, India \\ ${ }^{4}$ Sarla Hospital, Mumbai, Maharashtra, India \\ Indian J Plast Surg 2021;54:495-500.
}

\begin{abstract}
Address for correspondence Viral Desai, MS, MCh, DNB, CPLSS, 3rd Floor, Sarla Hospital, Dattatray Road, Santacruz West, Mumbai 400054, Maharashtra, India (e-mail: vrdesai@email.com).
\end{abstract}

\begin{abstract}
Keywords

- dissatisfied

- disgruntled

- disappointed

- dejected patients

A clinical study has noted that one out of six patients is perceived as "difficult" by clinicians. Not surprisingly, patient dissatisfaction has to do with multiple factors, both within and outside the control of the surgeon. In the present times of electronic information and ratings, managing difficult patients is a critical skill-a patient's dissatisfactory review could adversely affect a practitioner's reputation built over years of meticulous practice. Patient expectations are often more pronounced in case of elective medical procedures such as hair transplants. The subject of managing an unhappy patient in the context of hair transplantation is, therefore, one that requires due enquiry and is the subject that this article seeks to explore.
\end{abstract}

\section{Introduction}

Clinical onset of baldness in both men and women is generally around the age of 30-40 years. ${ }^{1,2}$ Unlike patients under pediatric care, geriatric care, or emergency care, the hair transplant patient cohort can be expected to be more expressive regarding its expectations and dissatisfaction. This article discusses the various types of patients that report for hair transplantation surgery, the factors contributing to the dissatisfaction of a hair transplant patient, the presentation of patient unhappiness, and the commonly suggested methods of patient dissatisfaction management. The article concludes with an insight on minimization of patient dissatisfaction by careful patient selection, proper execution of the surgical method, and prompt management of any postoperative grievances or complications.

\section{Why Unhappy Patients?}

According to the International Society of Hair Restoration Surgery (ISHRS) practice census, of men who had hair transplants, $64 \%$ were disappointed with their hair density after their procedure. In their research, Adams and Murray ${ }^{3}$ present a model which predicts patient satisfaction. This model identifies three factors that result in difficult clinical encounters and, consequently, unhappy patients: patient characteristics, surgeon characteristics, and situational characteristics. - Table 1 shows the classification of these factors in a summarized format.

On a similar note, other patient characteristics ${ }^{4}$ that have been cited as contributing factors to these challenging interactions include the following:

- Unrealistic expectations.

- Ignoring medical advice.

- Apparent dissatisfaction in care.

- Persistent complaints despite efforts to help.

- Insistence on being prescribed unnecessary drugs.

- Being verbally abusive and disrespectful.

Further, patients with an underlying depressive or anxiety disorders ${ }^{4,5}$ and somatic symptom severity (of greater than 6 on a 10-point scale ${ }^{6}$ ) are like to be more dissatisfied. Patients with underlying psychiatric disorders-body dysmorphic disorder in particular-are of particular concern in cosmetic published online

December 14, 2021
DOI https://doi.org/

10.1055/s-0041-1739249. ISSN 0970-0358.

\footnotetext{
(c) 2021. Association of Plastic Surgeons of India. All rights reserved. This is an open access article published by Thieme under the terms of the Creative Commons Attribution-NonDerivative-NonCommercial-License, permitting copying and reproduction so long as the original work is given appropriate credit. Contents may not be used for commercial purposes, or adapted, remixed, transformed or built upon. (https://creativecommons.org/ licenses/by-nc-nd/4.0/)

Thieme Medical and Scientific Publishers Pvt. Ltd., A-12, 2nd Floor, Sector 2, Noida-201301 UP, India
} 
Table 1 Factors that result in difficult clinical encounters

\begin{tabular}{|l|l|l|}
\hline Patient factors & Surgeon factors & Situational factors \\
\hline Angry, defensive, frightened, resistant & Angry or defensive & Language and literacy issues \\
\hline Manipulative & Fatigued or harried & Multiple people in the exam room \\
\hline Somatizing, grieving & Dogmatic or arrogant & Environmental issues \\
\hline Frequent visitors & & \\
\hline
\end{tabular}

surgery because these patients are unlikely to have realistic expectations from the surgery and, thereby, are less likely to be satisfied with the results of surgery. ${ }^{7}$ The evaluation of these conditions may be helpful as a counterindication for patient selection.

\section{Problematic Patient Personalities}

Some of the personality characteristics of difficult cosmetic surgery patients that have been previously documented in scientific literature are as shown in -Fig. 1.

In addition to these problematic personality categories, there may be other types of patients such as rude patients and know-it-all patients. These patients present a challenge to the surgeon, who should consider aligning the patients' expectations with the expected outcome of the hair transplant surgery as a sine qua non to admitting the patient under their care.

\section{Unhappy Patients in Hair Transplant Surgeries}

The sole rationale for performing aesthetic plastic surgery is to improve the patient's psychological well-being. ${ }^{8}$ Hair transplantation, although quite promising in its results, is a procedure that relies on a combination of factors to deliver the ideal result. Additionally, such results are evident over a period of time, after the transplanted hair enters the anagen phase. As such, patients presenting hair loss may experience dissatisfaction during the initial stages of their treatment (including at consultation) as well as during and after the procedure. We can categorize unhappy patients on the basis of the stage at which they demonstrate their grievance to have a closer understanding of the cause of their gripe. Being aware about the factors influencing these patients can help the surgeon intervene and prevent the complaint from escalating to an unmanageable level.

\section{At the Preoperative Stage}

The most effective way to manage an unhappy patient is simply to avoid operating patients who are likely to be unhappy with either the course of their treatment or with their surgical outcome. Administering the right patient selection criteria is the key role of the surgeon at this stage. Thus, the preoperative evaluation must include, in addition to the appraisal of the medical and aesthetic parameters, an assessment of the patient's psychological factors (see section on "Problematic Patient Personalities"). These difficult per- sonality traits have a tendency to become more apparent in the postoperative period. ${ }^{9}$ Deciding to undergo a medical procedure may be an anxiety-laden process for most patients. ${ }^{8}$ It is the role of the surgeon to counsel the patient, set right their expectations, and obtain informed consent at this stage. The "BATHE" technique ${ }^{10}$ is a psychotherapeutic screening test for anxiety, depression, and situational stress disorders procedure. It comprises four specific questions, each followed by an empathic response (-Fig. 2).

In addition to the BATHE technique, the surgeon should be aware of the patient's appearance and conduct. The indicators of a problematic personality of patient must be observed and documented.

\section{At the Operative Stage}

During the operative stage, patients may develop judgments regarding the surgeon's capabilities and the environment of the clinic in general. It may be advisable to have a standard operating procedure for the operative stage to ensure that the patient does not feel biased against owing to any deviation of the conduct of the clinical staff regarding one patient versus another. It is further necessary to consider the following factors as a part of the standard operating procedure framework to alleviate patient dissatisfaction (-Fig. 3).

A recent publication proposed the use of the $\mathrm{ROAR}^{11}$ (reflective, objective, assessment, reassurance) approach to moderate a difficult patient interaction (-Fig. 4).

ROAR involves reflecting the patient's distress, engaging the patient in the objective evaluation, providing an acknowledgment of the uncertain aspects of the plan of care, and providing the required reassurance to the patient.

\section{At the Postoperative Stage}

After a surgery-particularly an aesthetic surgery such as hair transplantation-a factor that causes discontentment among patients is dissatisfaction with the results. Many patients who may be cooperative during the surgery may turn hostile out of frustration if the expected results are not forthcoming or complications arise. The "BLAST" technique ${ }^{12}$ is a complaint-resolution method that is useful for patient care and as a clinical teaching tool (-Fig. 5).

Some of the discontentment of patients may be justified; hair transplantation surgery may cause complications. The topic of managing postoperative complications is a subject within itself. - Table 2 gives a summary of the possible complications that may arise after hair transplant surgery and an overview of their management. 


\title{
PROBLEMATIC PATIENT PERSONALITIES
}

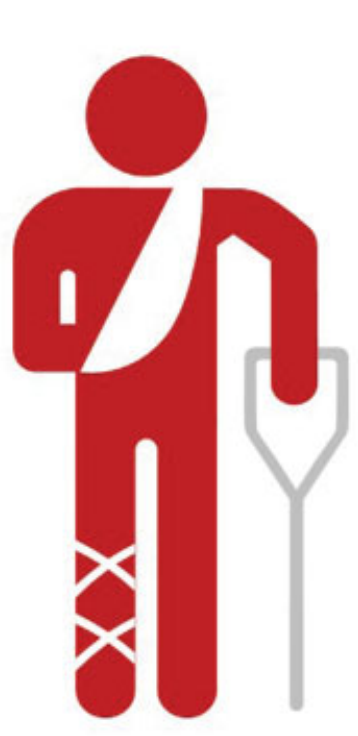

\author{
Patient with unrealistic expectations - want only "ideal" outcomes \\ Patient with unhappy tendency - demonstrate an overall unhappy demeanour \\ Patient with Body Dysmorphic Disorder - significant negative perception of surgical outcome \\ The overly-flattering patient - often quick to change opinions \\ The "Perfectionist" - unable to accept minor asymmetries \\ Patients with poor self-image - less likely to perceive benefit from aesthetic surgery \\ The "Laundry List" patient - comes with a long list of concerns \\ The "Cyberchondriac patient" aka "Google patient" - tend to do too much research on internet \\ The "Pessimistic" patient - may express scepticism and resentment \\ Patient with history of trauma - clue to the maladaptive or non-functional personality traits \\ VIPs - more likely to require extra attention \\ The "Poorly Compliant" patient - may adversely affect the outcome \\ The "Immediate Gratification" patient - require quick-fix treatments
}

Fig. 1 Personality characteristics of difficult cosmetic surgery patients.

\section{Tips to Avoid Unhappy Patients}

In addition to the specific case, there are certain guidelines that the surgical team must follow to avoid such a situation from arising.

- Expectation management. Be cautious against overpromising and underdelivering. Patients may have unreasonable expectations-such as envisioning a dense hair growth from the first month after the transplant itself, expecting a very dense result with relatively fewer grafts, and so forth. The surgeon has to tactfully manage such expectations before the procedure itself.

- Counseling. Some patients may experience frustration or alarm after the procedure. These patients require proper counseling regarding the outcome of their treatment and about what they could expect in the medium to long term.

- Postoperative instructions. Issuing clear written detailed postoperative instructions and answering patient queries are important to avoid patient dissatisfaction. The entire

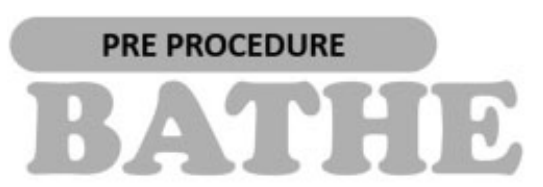

Background: How is your life and what is going on?

Affect: How do you feel about it?

Trouble: This must be troubling you, what bothers you most?

Handling: How are you coping-up with or handling this?

Empathy: This must be very difficult for you. postoperative course and outcome should be explained and documented in detail.

- Communications. It is necessary to have an open channel of communication with patients at all times, including after the procedure. It can be reassuring for the patient to have a way to discuss their apprehensions and feedback with the surgeon.

- Table 3 details the tips which may help to minimize unhappy patients.

\section{Tips to Manage Social Media Reviews}

While instances of patient dissatisfaction represent a minority of an aesthetic surgeon's practice, they can adversely affect the doctor-patient relationship. With the widespread use of social media, these instances may also reflect upon the surgeon's standing and reputation. It is important for a surgeon to manage not the clinical assignments, but also digital ones. The following may be a good set of rules for online reviews posted by patients.

- Be prompt. Respond to reviews at the earliest, especially to negative reviews. Avoiding bad reviews does not make them go away. Taking such comments head on shows that you are attentive and care about your patients' feedback.

- Use the right tone and words. A badly composed response to a negative response is a recipe for disaster. It may put the surgeon to risk of being perceived by the world as immature and spiteful. You can choose to be assertive and polite at the same time.

- Acknowledge the patient's key points. It is important to be brief and yet effective in your response. Others may not be able to appreciate long-winded and technical responses.

Fig. 2 BATHE technique. 


\section{ALLEVIATING PATIENT DISSATISFACTION}

\section{IN HAIR TRANSPLANT SURGERY}

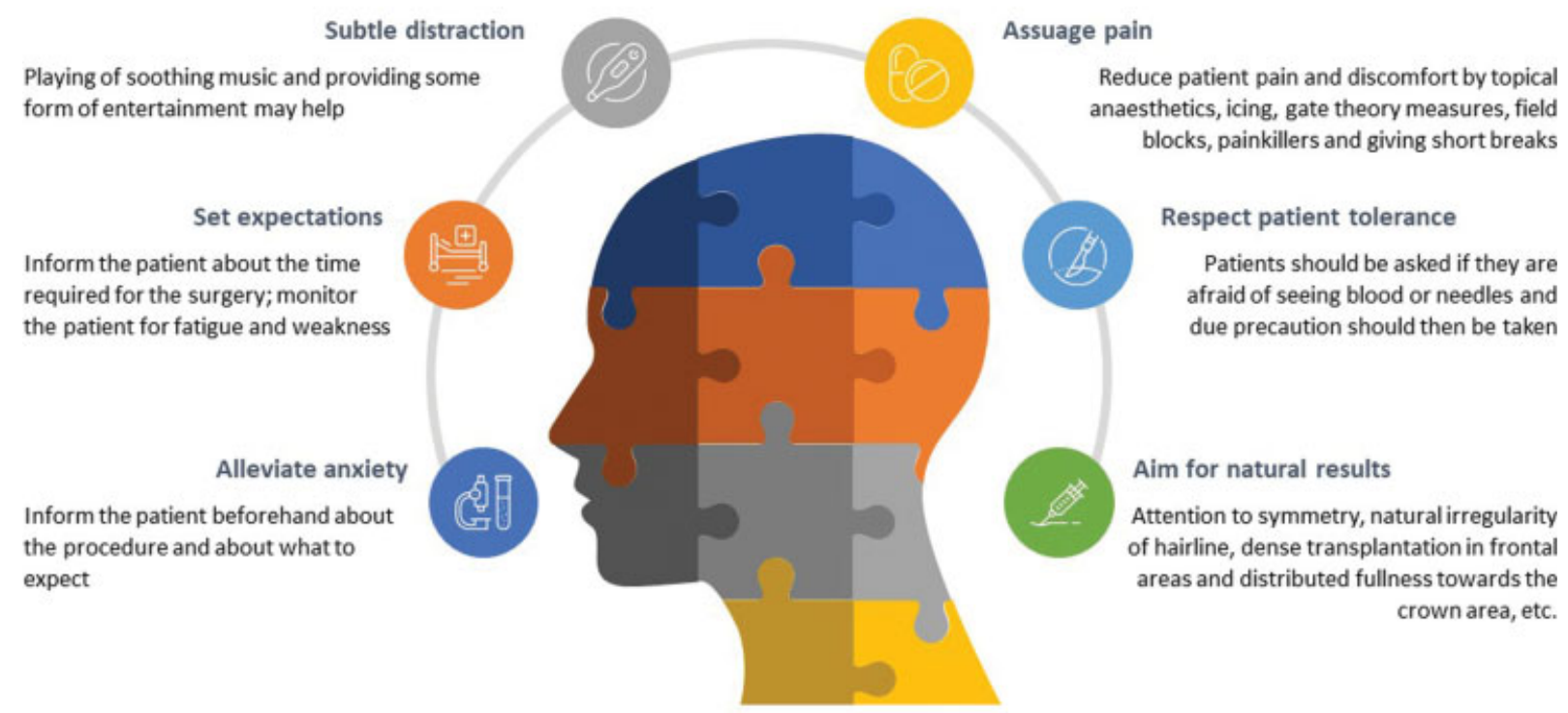

Fig. 3 Standard operating procedure framework.

\section{DURING PROCEDURE}

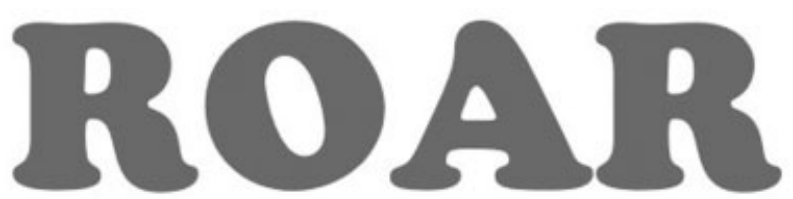

Reflective

\section{Objective}

\section{Assessment}

\section{Reassurance}

Fig. 4 ROAR approach.

- Proactively seek reviews. Not surprisingly, most of the patients that write online reviews are the ones who are unhappy and need a place to vent their feelings. Happy patients seldom announce their gratitude to the world, unless prompted. Provide a gentle prompt to your happy patients.

\section{Tips to Avoid Legal Malpractice Issues}

Early patient assessment and open communication are the key tools to manage dissatisfaction of the cosmetic surgery patient. That said, a standard operating procedure that includes thorough and accurate documentation of all clinic-patient interactions, including visitation records, acknowledgment of informed consent, and photographic documentation is highly recommended. These records ob-

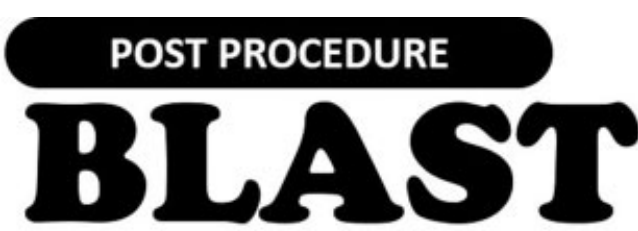

Believe: what the patient is saying

Listen actively: assess the patient's expectations

Apologize: for the patient's unmet expectations

\section{Satisfy the patient}

Thank: the patient for expressing their concerns

Fig. 5 BLAST technique.

jectively demonstrate improvements in the preoperative appearance that the patients may have difficulty appreciating by themselves. Unattended grievances may result in malpractice claims by unhappy patients. In such cases, the documentation as mentioned earlier would help provide a formidable defense against baseless legal claims. Additionally, in cases of malpractice claims these may help favor the judgment towards the doctor.

- Keep accurate documentation of all consultations, investigations, and procedures.

- Build a functional and trusting relationship with the patient.

- Take detailed accurate informed consent, maybe even a video consent.

- Maintain patient confidentiality.

- Attend to complaints promptly. 
Table 2 Possible transplant complications and management

\begin{tabular}{|c|c|c|c|}
\hline SI. & Complication & Presentation & Management \\
\hline 1. & Postoperative swelling & $\begin{array}{l}\text { Surgical edema at donor and } \\
\text { recipient sites }\end{array}$ & $\begin{array}{l}\text { Nonpharmacological management such as positioning, } \\
\text { head band, massage, and cold packs; medication may be } \\
\text { required in the form of corticosteroids (systemic and local) } \\
\text { and NSAIDS }\end{array}$ \\
\hline 2. & Crusting & $\begin{array}{l}\text { Forms in first } 24-48 \text { hours } \\
\text { after surgery and remains for } \\
\text { around 3-14 days after } \\
\text { surgery }\end{array}$ & $\begin{array}{l}\text { Wet compresses, frequent saline spraying, proper } \\
\text { cleansing of area, topical ointment, beta scrub washes, } \\
\text { dilute hydrogen peroxide wash, and antibiotics }\end{array}$ \\
\hline 3. & Wound dehiscence & $\begin{array}{l}\text { Infection, bleeding, } \\
\text { persistent pain, extensive } \\
\text { scarring }\end{array}$ & $\begin{array}{l}\text { Good patient selection and sound surgical techniques, } \\
\text { SMP treatment in the scar at a later stage, scar revision, } \\
\text { grafting into the scar }\end{array}$ \\
\hline 4. & Necrosis & $\begin{array}{l}\text { Unsightly scar, poor growth, } \\
\text { no result }\end{array}$ & $\begin{array}{l}\text { Skin grafting after ensuring return of blood supply to the } \\
\text { area, scar revision, transplant into the scar }\end{array}$ \\
\hline 5. & $\begin{array}{l}\text { Keloid or hypertrophic scar } \\
\text { formation }\end{array}$ & $\begin{array}{l}\text { Raised fibrotic } \\
\text { hyperinflammatory tissue } \\
\text { which in donor or recipient } \\
\text { sites, discharge, bleeding, } \\
\text { pain }\end{array}$ & $\begin{array}{l}\text { Good patient selection, sound surgical techniques, steroid } \\
\text { injections, and laser treatment. Avoid surgery in patients } \\
\text { prone to keloid, preoperative assessment }\end{array}$ \\
\hline 6. & $\begin{array}{l}\text { Donor hair effluvium and } \\
\text { scarring }\end{array}$ & $\begin{array}{l}\text { Can occur if a bigger size } \\
\text { punch has been used, } \\
\text { excessive donor area loss, } \\
\text { giga sessions, poor patient } \\
\text { selection }\end{array}$ & $\begin{array}{l}\text { Sound surgical techniques, use thin-walled smaller } \\
\text { punches, minimize transections, avoid harvesting too } \\
\text { close, avoid giga sessions. Preoperative and postoperative } \\
\text { medical therapy. SMP into the scars }\end{array}$ \\
\hline 7. & Folliculitis & $\begin{array}{l}\text { Usually as multiple small } \\
\text { papules and pustules, or cyst } \\
\text { formation or antibiomas }\end{array}$ & $\begin{array}{l}\text { Antidandruff shampoos, steroid lotion, treat the fungal } \\
\text { infection with antifungal shampoos, head wash before } \\
\text { surgery, proper aseptic precautions, sterilization of the } \\
\text { instruments, use of disposables, broad spectrum } \\
\text { antibiotics, betascrub washes, warm compresses, excision } \\
\text { of cysts, incision and drainage of pus, excision of } \\
\text { antibiomas }\end{array}$ \\
\hline 8. & Aesthetic complications & $\begin{array}{l}\text { Unnatural appearance, } \\
\text { scanty growth }\end{array}$ & $\begin{array}{l}\text { Patient counseling. Proper implantation methods like } \\
\text { correct depth, direction and angle, good illumination. } \\
\text { Limit the transection rate to } 2-10 \% \text {. Proper handling of } \\
\text { follicles, measures to ensure graft survival like hydration of } \\
\text { grafts, proper storage at correct temperature, graft time } \\
\text { out of body minimized. Proper principals like hairline } \\
\text { position, designing, accurate density, and distribution of } \\
\text { grafts }\end{array}$ \\
\hline
\end{tabular}

Abbreviations: NSAIDS, non steroidal anti inflammatory drugs; SMP, scalp micropigmentation.

Table 3 Points to be followed to minimize unhappy patients

\begin{tabular}{|l|l|l|}
\hline Points to be explained & $\begin{array}{l}\text { - Predict future hair loss } \\
\text { - Hair style to create better illusion of density } \\
\text { - Continuation of medical management } \\
\text { - Explain: combined medical and hair transplant gives best results } \\
\text { - Multiple sessions may be needed }\end{array}$ \\
\hline During the consultation & $\begin{array}{l}\text { - Realistic expectation } \\
\text { - Areas of most concern } \\
\text { - Number and layout of grafts } \\
\text { - Number of sessions required } \\
\text { - Possible density }\end{array}$ & $\begin{array}{l}\text { - Best possible outcome } \\
\text { - Cost of procedure } \\
\text { - Use of body hair } \\
\text { - Evaluation of body dysmorphic disorder }\end{array}$ \\
\hline & $\begin{array}{l}\text { - Pleasant experience } \\
\text { - Light music }\end{array}$ & $\begin{array}{l}\text { - Inform every step } \\
\text { - Show grafts and area to be covered } \\
\text { - No criticism and discussion }\end{array}$ \\
\hline
\end{tabular}


- Obtain medical malpractice insurance.

- Take professional legal advice in case of a potential problem.

Remember that as a general rule, malpractice is defined as the failure to provide the degree of care that another clinician in the same position with the same credentials would have performed, that resulted in an injury to the patient. ${ }^{13}$

\section{Conclusion}

The satisfaction of the patient an indicator of the quality of the health care service. Patient satisfaction depends on a good surgical outcome-which in turn relies on careful patient selection, proper execution of the surgical method, and prompt management of any postoperative grievances or complications. In hair transplant surgeries, the surgery can offer subjectively varying results. Adding to the subjectivity are factors beyond the surgeon-such as patient compliance; a default in this respect can lead to a less-than-ideal result and may add to the frustration of the patient and the surgeon. Thus, careful patient selection and transparent expectation management are the keys to positive outcomes and successful practice.

\section{Conflict of Interest}

None declared.

\section{References}

1 Mathers N, Jones N, Hannay D. Heartsink patients: a study of their general practitioners. Br J Gen Pract 1995;45(395):293-296

2 Khanna M. Hair transplantation surgery. Indian J Plast Surg 2008; 41(Suppl):S56-S63

3 Adams J, Murray R III. The general approach to the difficult patient. Emerg Med Clin North Am 1998;16(04):689-700, v

4 Hull SK, Broquet K. How to manage difficult patient encounters. Fam Pract Manag 2007;14(06):30-34

5 An PG, Rabatin JS, Manwell LB, Linzer M, Brown RL, Schwartz MDMEMO Investigators. Burden of difficult encounters in primary care: data from the minimizing error, maximizing outcomes study. Arch Intern Med 2009;169(04):410-414

6 Hahn SR, Kroenke K, Spitzer RL, et al. The difficult patient: prevalence, psychopathology, and functional impairment. J Gen Intern Med 1996;11(01):1-8

7 Sarwer DB, Crerand CE. Body image and cosmetic medical treatments. Body Image 2004;1(01):99-111

8 Bensing J, Verheul W, van Dulmen AM. Patient anxiety in the medical encounter: a study of verbal and nonverbal communication in general practice. Health Educ 2008;108:373-383

9 Sykes JM. Managing the psychological aspects of plastic surgery patients. Curr Opin Otolaryngol Head Neck Surg 2009;17(04):321-325

10 Lieberman JA III, Stuart MR. The BATHE method: incorporating counseling and psychotherapy into the everyday management of patients. Prim Care Companion J Clin Psychiatry 1999;1(02):35-38

11 McCarthy JG, Cheatham JG, Singla M. How to approach difficult patient encounters: ROAR. Gastroenterology 2018;155(02): 258-261

12 Steinman HK. A method for working with displeased patientsblast. J Clin Aesthet Dermatol 2013;6(03):25-28

13 Bono MJ, Wermuth HR, Hipskind JE. Medical Malpractice. Treasure Island, FL: StatPearls Publishing; 2021 